\title{
Scientific Analysis of the Commonness in Human Civilization
}

\author{
Yue Yang \\ Guangzhou 510425, China \\ E-mail: yyllqq2007@163.com
}

\begin{abstract}
Contrary with the opinion and idea that the civilization difference induces the civilization conflicts, the commonness of civilization is more important in fact. In the various past researches about the civilization comparison, most scholars emphasized to review and look the differences among different civilizations, and deduced that the differences induced the conflicts. However, the differences among various civilizations are only one aspect of the fact, and on the other hand, the commonness exists among different civilizations. From many aspects such as common system, common earth, common goals, common opportunities, common threats, common benefits and common deficiencies, we scientifically analyzed the commonness among the human civilizations.
\end{abstract}

Keywords: Globalization, Human advance, General characteristics of civilization, Scientific analysis

The word of "civilization" has two meanings, and the one meaning is to indicate the advance degree that human break away from the state of blindness and wildness, and the other meaning is the division unit which exceeds the country and nationality in the human system. In the writings about the civilization, there are always the alternative uses of two meanings, so is this article. In past comparison researches of various civilizations, most scholars emphasized to review and find the differences among them, and deduced that these differences would induce the conflicts. However, the differences existing in various civilizations are only one aspect of the truth. On the other hand, the commonness exists among various civilizations. For the commonness of the civilization, human still have not sufficient cognitions, and when the human have entered into the age of globalization, we should repair this limitation of the cognitions.

Facing the conflicts of civilization, when people are wild about exploring the differences of civilization, we should urgently act in a diametrically opposite way, i.e. find the commonness among various civilizations. To find the commonness among various civilizations is the hope to seek common points while reserving difference in different civilizations, walk out the abysm of conflict, and go to the harmonious royal road.

\section{Common system}

There are exclusive human being in the earth, even in the known universe and space so far, so the civilization of human being is exclusive, and it can equal to the world civilization or the earth civilization, and it is the civilization possessed by the whole human being. Certainly, the human civilization is the system with complex compositions and diversiform configurations. As a system, the human civilization is exclusive. The so-called various civilizations divided by people are just the sub-civilizations in the human civilization system. As various civilizations with all types are the human civilization, they should possess the common attributes of the civilization such as the commonness of the human civilization, the commonness of the world civilization, the commonness of the earth civilization. The commonness of the human civilization is the essential attribute of the human civilization.

The commonness of human civilization is based on the commonness of humanity. Like the mathematical model, the differences of humanistic commonness are only different parameters, and like the physiological structure, the differences of humanistic commonness are only different appearances. With the beautiful aspect, the humanity certainly has the deficient aspect. The beautiful humanity is certain, and the deficient humanity is practical. The humanistic basic antinomy is not only the antinomy between the nicety and the fault, but the antinomy between the certainty and practice. The whole human civilization history can be deduced by the basic antimony of the humanity.

Not only the commonness and differences co-exist in various civilizations, but they have primary and secondary sequences. The commonness of civilization is in the dominant status and exerts the leading function.

\section{Common earth}

In the universe, the civilization is the particular patent of human being. In all ages, human being comes into the world and survives in the only earth. In the far past, human didn't come from multiple planets, and at present, human can not survive in multiple planets. Supposed that human come from multiple planets or human survive in multiple planets, the different essential civilizations may exist between earthman and extraterrestrial being.

In fact, the survival age of human being is very short. "Comparing with the long history of the earth, the time that human lives in the earth is not long. In the past, human always thought the human age was 500 thousands years, but the 
new research results indicated that the age of human was 700 thousands years, even might be 900 thousands years. Even so, we can not forget the proportion, i.e. the human age is only one in a thousand of the age of earth (Zhou, 2003, P.3)". Human being has common origin and common evolvement course. The difference between the human being and animals far exceeds the differences among human races and nationalities. The differences about the complexion, language, custom and religion among human races and nationalities are only the exterior, and human being's talent showing itself in many aspects such as physiology, labor, sense, morality and emotion from the animal kingdom is the interior. The difference among peoples is finally less than the difference between the human being and inhuman, and the commonness among peoples is finally more than the commonness between the human being and inhuman.

In space, the survival range of human being is very narrow in fact. The human being with thousands years' civilization history has gradually known the panorama of the earth in recent hundreds years. The astronomical radio telescope has detected the planets which were from tens billions light-years in the universe, and the earth lived by the human being in the vast universe is an insignificant particle. "The earth where we live is just a ceaselessly rotary asteroid in the tiny Milky Way galaxy, and comparing with the whole universe, it is very small as a dust in the Pacific (L. S. Stavrianos, 1999, P.63)". On the desktop of the universe, the tiny earth can be observed only by the microscope. The earth not only looks tiny in the astronomical scale of the universe, but with the advance of human science and technology, the scale will further change. The advances of the traffic tools make the human being span the natural obstacles in the earth to travel with high speed. The advances of the communication tools make the human being span the natural obstacles in the earth to communicate each other. The traffic and communication reduce the space distances among peoples in different regions and different positions. From that meaning, the earth is diminishing relatively.

The earth is the common life ark for all humankind. The population leap is making the life ark become more and more crowded. Though human being are distributed in different regions of the earth, but the earth ecological system is an organic macrocosm for the humankind. In front of the earth ecological system, we have no other choices except we are in the same boat. Human have common demands for various natural resources such as water, air, land and mine. The catchword in Beijing Olympics Game is "one world, one dream" and the reality of human history is that "one earth, one home". Human lives in common earth, common land and common sky. The absolutely irreconcilable relation among humans is very absurd.

\section{Common goals}

Civilization is not only the common career for human being, but also the common ideal hope for humankind. The bourn between the civilization and the blindness and wildness is entirely different. Human being is pulling away from the blindness and wildness to obtain the liberation and go to the civilization. There are two foundation stones for the human civilization, i.e. the relation among peoples and the relation between the human being and the nature. For the human civilization based the relations among peoples, all peoples yearn towards peaceful, safe and plentiful world, and all peoples look forward to just and flourishing society. The human civilization, environment protection and sustainable development based on the relationship between the human being and the nature have exceeded the interior limitations of the human being and been the advance direction confirmed by the human being.

The civilization course is also the course that human perfect themselves. From of old, human being always pursues common beautiful values. Contrary to the worth sense difference among different cultures, peoples living in any cultural backgrounds will appreciate same excellent qualities such as hardworking, assiduity, brave, adamancy, brightness, wittiness, kindheartedness, friendliness, honesty and keeping faith. These excellent qualities are recognized by all human being, and though many peoples can not realize them in fact, but as the value rules, they are identical in different value views. The value views of any races, any countries, any nationalities and even any tribalism will not advocate abominable views such as idleness, nonfeasance, poltroonery, flabbiness, blindness, peremptoriness, bloodiness, ruthless, guile and cheat which are chided in any cultural value view, and no body will take them as an honor. The excellent qualities are the same with not only individuals, but also nationalities. Hardworking and brave nationality is also regarded as the recognition full of prides. Almost all nationalities are happy to accept thus recognition. In fact, all nationalities in the world are hardworking and brave nationalities, and there is no one nationality to be defined as the lazy and faint-hearted nationality.

\section{Common opportunities}

Facing difficulties and crises, confidence, courage and hope are human special active psychological reactions for any individual, nationality or country. But all active psychological reactions should be enhanced to the global layer. The confidence, courage and hope are the confidence, courage and hope that all peoples walk out the corner, realize the mutual benefits and win-win, and go to the bright foreground, and they are not the traditional confidence, courage and hope about conquering among individuals, or nationalities or countries.

The beacon light which leads human being to leave the animal kingdom and go ahead continually is the sense in the deep soul of humanity. The course of human advance is the increase of extension and sense, and it is an alternant and 
progressive course. The increase of human sense is mainly represented in the scientific advance, i.e. the innovation of scientific theories and systems, and the accumulation of scientific knowledge and technologies. All suspicions and arraignments for the science are temporary, and they can be gradually clarified and eliminated with the time. The opinion that the science is the double-edged sword is blundering, and it will induce and deepen the mistake for the science. Whether in the early life of human being or in the modern life, the use of fire is very important, but it will induce the fire disaster, so the fire is also the double-edged sword like the water, because certain useful invention or certain profitable things will produce certain negative function under certain conditions, and we should not refuse to do what one should for fear of running a risk. According to human practical experiences, the double-edged sword is not the problem that can not be solved. Human completely can face the science just like water and fire. As viewed from the science system, the development of the science is not balanced so far, though the human being has obtained historical breakthrough and decisive result when scientifically exploring the nature. If the humanity can equally push the scientific explorations in the human domain and the social domain, that will be the resplendent celebration for completion of the building of human civilization.

To scientifically know the world is the necessary premise to change the world according to human demands and wills, and to change the world is the final goal of knowing the world. The modern natural science has acquired significant advancements, and the cognition level to the objective world has exceeded certain limitation, and to change the world by human demands and wills has been realized in many aspects. When both the human science and the social science acquire same significant advancements, it will be realized to change the subjective world according to human demands and wills.

\section{Common threats}

The human being is facing common threats and the global crisis induced by these threats. That is not the alarmism, but the austere fact. The biggest threat to the human survival comes from the behavior that the humanity falls away from its civilization. Except for that, there are not any exterior powers which can threaten human survival.

In the history, human fought for life and death in countless wars, but they are not in the whole survival state at present. The two world wars in the twentieth century achieved the peak of cannibalism among peoples, which indicated that human sense was so brittle. The research and use of many weapons of mass destruction such as atom bomb, biological weapon and chemical weapon had pushed the humanity to the suicidal cliff. The uncivilized behaviors except for the war are quite serious. The influences of the drugs are not divided by the race and nationality. The terrorists' execution and destruction have affected the whole world aiming at human body and spirit. The increasing gap of wealth is still the pendent problem for the world. The corrosion of corruption has gone into every corner of the society.

There were numerous natural disasters in the history, but the world has not faced the ecological crisis like the present. The plunders to the land, forest, mine and water resource and the damage to the ecological environment have pushed the human being to the grave for the humanity themselves.

The human psychological structures and mechanisms are identical in fact. Human will suffer same illnesses and same invasions from same virus. The sufferings of various illnesses are same to European, Asian, African and American. Different races and nationalities have same immunities. The occurrences and prevalence of various diseases are threatening the family of human being, which needs human common endeavors to control the diseases.

\section{Common benefits}

Standing on the universal position, the sovereign global benefit and human benefit have occurred and formed, which needs all peoples from different countries and nationalities to maintain together. To do that, the premise is that the cognition should achieve corresponding altitude. Peoples should exceed original sovereign national benefits, and clearly identify with the new sovereign global benefits and human benefits to achieve the consensus about the global benefit and human benefit.

The global benefit and human benefit contains all national benefits to the largest extent. So to recognize and maintain the global benefit and human benefit in the cognition and practice doesn't breach the national benefit. Comparing with the global benefit and human benefit, the former national benefit is only local and narrow benefit. In front of the common threats and global crises, if we ignores the global benefit and human benefit, only maintain our own national benefit, we will be perished together.

For the individuals, the national benefit is certainly great and scared, but on the layer of the global benefit and human benefit, we need to reconsider the doings of many countries and nationalities. In the conflicts among countries and nationalities, the hero of one country or one nationality may be the enemy of another country or another nationality. Because of the bigness, elevation and holiness of the country and nationality, the actions by the name of the country and the nationality will have more deceptive and intimidatory functions to make all living things have to follow like sheep. In the history, numerous human infamies, deviltries and crimes happened by the camouflage of the country or the nationality. 
If we still persist in the supremacy of the country or the nationality and pursue the profit maximization of one country or one nationality in the globalization era, not only the benefits of other countries and nationalities but also the global benefit and the human benefit will be harmed. The benefit view in the globalization era is that the global benefit and human benefit are higher than the national benefits. When the beneficial conflicts occur among countries or nationalities, we should give way to ensure the global benefit or the human benefit.

\section{Common deficiencies}

According to the meanings of the civilization getting rid of the blindness and wildness, the human history is still in the state of half-civilization. "By the nature of the civilization, there are two kinds of civilization. The first one is the civilization between the humanity and the nature, which is generated and developed in the relationship between the humanity and the nature. The second one is the civilization among peoples, which is generated and developed in the relationship among peoples. Up to now, in the development of human society, there are not only the glory and resplendence of the civilization, but the uncivilized sins and darkness, so the process of the second sort of civilization is still in the half-civilization and half-wildness stage (Yang, 2008, P.102)". Not only individual uncivilized phenomena still exist universally, but also the representations of the country and nationality are uncivilized also to the large extent.

The behavior characteristic of country or nationality is very similar with individual's behavior characteristic. The behaviors of country or nationality are not always distingue, and even some of them are despicable. In the international relationships taking the country or the nationality as the behavior subject, bad phenomena such as pride and prejudice, mistake and suspicion, cheat and cabal, peremptoriness and shamelessly action, greed and flaunt were commonly seen. On the confused international stage, some countries and nationalities always use their strength to bully the weak for the external affairs. Many very solemn international friendly agreements could not be tested in the time. Large numbers of formal international treaties lost the sanction when the ink marks had not dried.

Individual ignominious behaviors will be restricted by the social consensus, morality and laws, but the ignominious behaviors of the country or the nationality are always defended and covered by the name of the country or the nationality to enjoy the immunity to some extent. Therefore, those individuals who represent the nation or the nationality will have nothing to fear when they make false decisions. When every country or nationality starts the war or is drifted into the war, he always put the national benefit on the first state.

The worried civilization conflict is related with not only the differences among various civilizations, but also the commonness of various civilizations. For example, two people who are same selfish or same jealous, how they will establish the harmoniously stable relationship. When everyone wants to father his wills upon others and will not accept others' dominances, the conflicts will occur among individuals, so is the country or the nationality. The common deficiencies existing in all countries will compose in the negative influences which will more easily induce the mutual conflicts than the differences in various civilizations.

The consciousness and the potential consciousness opened by the Freud's psychology exist not only in individuals, but in the society, the nationality or the country. Through the deep researches, we will find that the individual consciousness and the potential consciousness are always dissociable, that is why the individual will gent into the painful ideological struggle. In the intercourse among individuals, one person's consciousness usually can be harmonized with other's consciousness, and one person's potential consciousness will always conflicted with the other's potential consciousness, that is why two persons with same wills and benefits will get into the dissension without reasons. So are two or multiple countries or nationalities. The deviation of the consciousness and the potential consciousness will largely increase the probability of the antinomies and conflicts on various layers from the microcosmic to the macrocosmic, and largely increase the difficulty and costs to solve the antinomies and conflicts.

Both the humanity and the human civilization are facing the mutual future. Because the biggest threat to the human survival comes from the human being, so it can only depend on the human being to eliminate the threat and crisis. Except for that, there is no any exterior powers can decide human future and destiny. The commonness of human civilization will be noticed and researched by more and more scholars and government figures early or late. In Huntington's "The Clash of Civilizations and the Remaking of World Order", he mainly discussed the differences and clash of civilizations, and pointed out that "the coexistence of cultures needs to look for the commonness of most civilizations, which is not to promote the universal characteristic of certain civilization in the hypothesis. In the world with multiple civilizations, the constructive road is to abandon the universalism and accept the diversity and look for the commonness (Samuel, 1998, P.369)" from another aspect. In the inaugural, US President Obama said, "As the world is becoming smaller and smaller, we believe the mutual humanity and morality of human being will appear automatically one day". And based on the foundation of human mutual humanity and morality, the monument of human civilization commonness will be lifted highly.

\section{References}

L. S. Stavrianos, interpreted by Wu, Xiangying \& Liang, Chimin. (1999). The World since 1500: A Global History. 
Shanghai: Shanghai Academy of Social Science Press. May of 2003. P.63.

Samuel. P. Huntington, interpreted by Zhou, Qi et al. (1998). The Clash of Civilizations and the Remaking of World Order. Beijing: Xinhua Press. March of 1998. P.369.

Yang, Yue. (2008). Systems Analysis of Globalization. Journal of Politics and Law. No.4. P.102.

Zhou, Hailin \& Xie, Gaodi. (2003). Human Survival Corner: the Paradox of the Development. Beijing: Social Sciences Academic Press. Sep. of 2003. P.3. 